\section{ABSTRACT}

\title{
Butanol as cosolvent for transesterification of rapeseed oil by methanol under homogeneous and heterogeneous catalyst
}

\author{
Martin Hájek ${ }^{* 1}$, Aleš Vávra ${ }^{1}$ \\ ${ }^{1}$ Department of Physical Chemistry, Faculty of Chemical Technology \\ University of Pardubice, Studentská 573, 53210 Pardubice, Czech Republic \\ *Correspondence author: martin.hajek@upce.cz
}

The paper is focused on the use of methanol (M) or ethanol together with butanol (B) in the transesterification of rapeseed oil $(\mathrm{O})$ under homogeneous $(\mathrm{KOH})$ and heterogeneous catalysis (Mg-Fe mixed oxides). The advantage of using butanol consists in the formation of homogenous reaction mixture (increases the reaction rate, i.e. decreasing of reaction time) and higher caloric value of formed esters. The novelty consist in the use of mixture of alcohols. The ternary plots of reaction components (alcohols and oil) were measured at 25 and $60{ }^{\circ} \mathrm{C}$. For homogeneous catalyst, the influence of (i) the molar ratios of reaction components, (ii) the temperature, (iii) the amount of catalyst and (iv) the way of transesterification stopping on the course of transesterification was studied. The properties of esters phase and also glycerol phase were determined including ester loss in the glycerol phase. The ester yield was $97 \%$

after $10 \mathrm{~min}$ of reaction for $60^{\circ} \mathrm{C}$ and the ratio O:M:B was 1:6:2, which is significantly 8 decreasing of time in comparison with methanol only $(90 \mathrm{~min})$. However, the content of 9 potassium ions was higher, because butyl ester caused higher solubility of potassium ions. For 
20 heterogeneous catalyst, the synthesized materials were characterised by chosen method and

21 tested in transesterification with methanol, butanol and their combination.

\section{KEYWORDS}

transesterification; biodiesel; esters; butanol; methanol

\section{NOMENCLATURE}

B

butanol

$27 \quad \mathrm{BE}$

28 E

29 FAME

30 GC

$31 \mathrm{M}$

$32 \mathrm{ME}$

$33 \mathrm{O}$

$34 \mathrm{EP}, \mathrm{GP}$

35

36

37

38

K

$39 \quad T$

40

41

42

TG, DG, MG

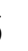
(1)

$t$

1

\section{water}

$w_{\text {ester }}^{G P}$

$43 w_{\text {ester }}$

$44 \quad w_{\text {glycerol }}$

$45 \quad w_{G f}$

$46 \quad w_{I S}$

$47 \quad w_{M G}, w_{D G}, w_{T G}$

$w_{S}$

49

oil butyl ester

ethanol

fatty acid methyl ester

gas chromatography

methanol

methyl ester

the ester phase, the glycerol phase

triacylglycerides, diacylglycerides, monoacylglycerides; all of these substances are referred to as glycerides

concentration of potassium ions $\left(\mathrm{mg} \mathrm{kg}^{-1}\right)$

reaction temperature $\left({ }^{\circ} \mathrm{C}\right)$

reaction time $(\mathrm{min})$

water content in the EP (ppm)

ester content in the GP (wt.\%)

ester content in the EP (wt.\%)

glycerol content in the GP (wt.\%)

glycerol content in the EP (wt.\%)

content of inorganic salts in the GP (wt.\%)

content of MG, DG and TG in the EP (wt.\%)

soap content (wt.\%)

water content in the GP 
$x_{B}, x_{E}, x_{M}, x_{O}$

mole fraction of butanol, ethanol, methanol and oil in the mixture (-)

$x_{B E}^{E P}$ butyl esters content in the EP (mol.\%)

$x_{M E}^{E P}, x_{M E}^{G P}$

\section{INTRODUCTION}

The mixture of methyl esters of higher fatty acids (biodiesel) is a biofuel for combustion engines made from biomass. It is produced by the transesterification of triacylglycerides (TG) contained in vegetable oils or animal fats by low molecular alcohols. The transesterification has to be catalysed under mild reaction conditions, without any catalyst it proceeds only under higher temperature and pressure - at the supercritical fluid [1]. A basic homogeneous catalyst is the most often used [2] [3]. However, the heterogeneous or enzymatic catalysis is also applicable to ester preparation [4] [5].

The most often used alcohol is methanol, the use of other types of alcohols, such as ethanol [6] or butanol is less common. Methanol and ethanol are immiscible with TG, i.e. the heterogeneous mixture is formed and the transesterification proceeds only on the interface. This is in contrast to butanol, which is miscible with TG. To increase the reaction rate (i.e. to shorten the reaction time) for methanol or ethanol, the reaction mixture has to be intensively stirred to increase the interface area. Other possibility is the formation of a single phase by addition of another solvent (called cosolvent), which is inactive to oil and alcohol. The use of several cosolvents, mostly for homogeneously catalysed transesterification, was published, such as dimethyl ether [7], di-isopropyl ether, tetrahydrofuran [8], [9], acetone, methyl tertbutyl ether [10]. Butanol (most often 1-butanol) can be also used as a cosolvent for transesterification with methanol/ethanol, because dissolves TG and methanol/ethanol. Moreover, butanol reacts with oil to form butyl esters. The use of butanol was published almost only as the reaction component for many types of catalysts, such as homogeneous basic catalyst $\mathrm{KOCH}_{3}$ or $\mathrm{KOH}$ [11], homogeneous acid catalyst [12] [13] or heterogeneous 
catalyst [14]. However, the detailed analysis of both phase including ester loss are very often omitted. For enzymatic catalysis (Thermomyces lanuginosa), methanol together with butanol was published, but without determination of homogeneous region [15]. The transesterification with only butanol usually proceeded at higher temperature $\left(100-115^{\circ} \mathrm{C}\right)$ and higher molar ratio of oil to butanol than for methanol [16], because it is less reactive than methanol. However, the synthesized butyl esters have higher caloric value than methyl esters (approximately about 7-10\%) [17].

Almost all papers dealing with transesterification are focused only on the use of single type of alcohol (some of them with inactive cosolvents) and none of them on the combination of both alcohols. The novelty of the paper consists in the use of butanol, which was employed as a cosolvent and also as the reaction component in the transesterification of oil, together with methanol or ethanol. The relevance of butanol use consists in (i) shortening of the reaction time and (ii) slightly higher caloric value, because the main product is a mixture of methyl or ethyl esters with butyl esters. The purpose of ternary plots was to find the region, where the reaction components were presented in a single phase. The parameters, which can influence the course of transesterification and properties of ester (EP) and also glycerol phase (GP), such as the molar ratios of oil, methanol and butanol, the reaction temperatures, the catalyst amount and the way of transesterification stopping, were studied. The attention was also paid to the distribution of esters according to alcohols and loss of esters in the GP, which is often omitted in papers. The use of two types of alcohols together, including determination of ternary plots, has not been published yet regarding homogeneously or heterogeneously catalysed transesterification. Its description is the main aim of the paper. 


\section{MATERIALS AND METHODS}

99

100

101

102

103

104

105

106

107

108

109

110

111

112

113

114

115

116

117

118

119

120

121

\subsection{Ternary plot}

The ternary plot was determined by measuring of transmittance by spectrophotometric method at wavelength $450 \mathrm{~nm}$ at two temperatures $\left(25\right.$ and $\left.60^{\circ} \mathrm{C}\right)$. The transmittance of pure oil was $100 \%$. The oil and methanol (or ethanol) were stirred together and heterogeneous system with low transmittance was formed. Butanol, which is miscible with both liquids, was successively added and transmittance was monitored. When the transmittance rapidly increased, the system became homogeneous, which was one point of binodale curve of ternary plot. This method was used for determination of each binodal point. The molar ratios of components were used for formation of the final plot in program Origin 9.1. The rapeseed oil (molar mass $879.1 \mathrm{~g} \mathrm{~mol}^{-1}$ ) was considered as a chemical individuum.

\subsection{Transesterification of oil}

Homogeneous catalyst: The rapeseed oil (free of erucic acid, acid number $0.2 \mathrm{mg} \mathrm{KOH} \mathrm{g}{ }^{-1}$, water content $650 \mathrm{mg} \mathrm{kg}^{-1}$ and density $920 \mathrm{~kg} \mathrm{~m}^{-3}\left(15^{\circ} \mathrm{C}\right)$, produced by Lukana, Czech Republic) was put into the reaction vessel and thermostated to the reaction temperature. The catalyst $\mathrm{KOH}$ (purity 85 wt.\%, Lach-Ner, Neratovice, The Czech Republic) was dissolved in mixture of methanol (p.a., Penta, The Czech Republic) with butanol (purity 99.5\%, Penta, The Czech Republic) and mixture were also thermostated to the temperature of reaction. The mixture of alcohols with catalyst was quickly added into the reaction vessel. Throughout the reaction time, the reaction mixture was sampled and the content of mono-, di- and triacylglycerides was determined. The reaction was stopped by catalyst neutralization by (i) gas carbon dioxide as a week acid [18] or (ii) phosphoric acid as a strong acid [19]. The acids had been dosed approximately for 5 min until the $\mathrm{pH}$ fell to the minimum value, which was approximately 8 for carbon dioxide and 10.5 for phosphoric acid. The paddle stirrer was set to 
$300 \mathrm{rpm}$ during the reaction and neutralization. The alcohols excess was removed by

123 distillation; the reaction mixture had been evaporated for $40 \mathrm{~min}$ at $100^{\circ} \mathrm{C}$ at the pressure of approximately $3 \mathrm{kPa}$. The mixture was put into a separatory funnel and separated by gravity for $24 \mathrm{~h}$ and then both formed phases (the ester and glycerol) were analysed.

126 Heterogeneous catalyst: Mg-Fe mixed oxides were synthesized from hydrotalcite by heating

127 (calcination) to $450{ }^{\circ} \mathrm{C}$ for $3 \mathrm{~h}$. The hydrotalcite was synthesis by co precipitation from

128 nitrates of magnesium and iron according to [20]. Moreover, the active coal (1.25 wt\% to 129 amount of precursors) was added during synthesis to increase the specific surface area. The 130 reaction was carried out in stainless steel batch autoclave (300 ml, Parr company, USA) 131 equipped with shaft stirrer. The transesterification was carried in $300 \mathrm{ml}$ batch reactor (Parr,

132 USA). The reaction conditions were: molar ratio alcohol to oil $24: 1,1 \mathrm{wt} \%$ of catalyst to input 133 rapeseed oil, reaction temperature $120{ }^{\circ} \mathrm{C}$ and stirring speed $300 \mathrm{rpm}$. After heating to the 134 reaction temperature, the stirring was switched on and the reaction was initiated. After 135 reaction time, the catalyst was removed by filtration and methanol by distillation from the 136 mixture $\left(75^{\circ} \mathrm{C}, 3 \mathrm{kPa}\right)$ and formed phases was analysed, especially ester content in the EP.

\section{2.3. Analytical method}

138 The contents of glycerides were determined by gas chromatography (GC) with flame

139 ionization detector by the method according to EN 14105 by Shimadzu GC-2010 with the

140 help of linear calibration curves (monoolein, diolein and triolein were used as standards), the 141 determination is described in detailed [19].

142 The content of potassium ions in the EP were determined by flame photometry (Flame

143 photometer 410, Sherwood Scientific Ltd, United Kingdom). The flash point of the EP was

144 measured by the Pensky-Martens closed-cup method (EN ISO 2719) with the instrument OB-

145305 (MIM Fabri, Hungary). The water content in both phases was determined according to 
146 EN ISO 12937 (TitroLine ${ }^{\circledR}$ 7750) and the alcohol content also in both phases was determined 147 by GC [21].

148 The contents of basic matter (potassium hydrogen carbonate, potassium carbonate, $149 \mathrm{~K}_{2} \mathrm{HPO}_{4}$ and soaps) were determined in the GP by acidimetric titration by $\mathrm{HCl}\left(0.1 \mathrm{~mol} \mathrm{dm}^{-3}\right)$ 150 with potentiometric identification. The content of glycerol and esters (i.e. esters loss) 151 including the distribution according to alcohols (methyl and butyl esters) in the GP was 152 determined by HPLC [19].

153 The heterogeneous catalyst was characterised by X-ray Powder Diffraction (XRD) with 154 the help of JCPDS database for confirmation of structure of material, inductively coupled 155 plasma (ICP) to determine the real content of metals and N2-isotherme to determine the 156 surface area [20].

\section{3. RESULTS AND DISCUSSION}

\section{$158 \quad 3.1$. Ternary plots}

159 Firstly, the ternary plots for methanol (M) or ethanol (E), rapeseed oil (O) and butanol (B) 160 were determined at two temperatures 25 and $60{ }^{\circ} \mathrm{C}$ (Fig. 1). The reason was to find the molar 161 ratios of components, so that the reaction mixture was homogeneous, because the miscibility 162 depends on the molar ratio of components.

163 The heterogeneous region was larger for methanol than for ethanol at both temperatures.

164 The reason is that the properties of butanol are more similar to ethanol than to methanol, 165 especially the dipole moment, which reflects the polarity of chemicals. The dipole moment of 166 butanol $\left(5.54 \cdot 10^{-30} \mathrm{C} . \mathrm{m}\right)$ is approximately the same as of ethanol $\left(5.84 \cdot 10^{-30} \mathrm{C} . \mathrm{m}\right)$ and

167 different from methanol $\left(9.57 \cdot 10^{-30} \mathrm{C} . \mathrm{m}\right)[22]$. The heterogeneous region was larger at $25^{\circ} \mathrm{C}$ 168 for methanol and also ethanol, which was expectable, because the miscibility usually 
169 increases with increasing temperature. For ethanol at $60{ }^{\circ} \mathrm{C}$, the mixture was homogeneous at 170 almost all molar ratios.

171 Moreover, the molar ratios of oil to methanol (from 1:3.6 to 1:6) or oil to ethanol (1:7),

172 which were used for transesterification, were plotted (Fig. 1).

173

174

175

176

177

178

179

180

181

182

183

184

185

186

187

188

189

190

191

\subsection{Transesterification by homogeneous catalyst}

The transesterification depends on the various reaction conditions, such as alcohol type, the reaction temperature and time, the molar ratio of initial components and the amount of catalyst.

Firstly, the transesterification with ethanol and butanol together was carried out at $25^{\circ} \mathrm{C}$, at molar ratio O:E:B 1:7:3.5 and $1 \mathrm{wt} \%$ of catalyst $(\mathrm{KOH})$ to oil. The lower temperature $\left(25^{\circ} \mathrm{C}\right)$ was chosen, because the undesired oil saponification proceeds less than at $60{ }^{\circ} \mathrm{C}$ [23]. The molar ratio of reaction components was based on ternary plot (Fig. 1B), so the reaction mixture was in the single phase. After separation, both phases were analysed. However, the content of potassium ions in the EP was very high $\left(15 \mathrm{~g} \mathrm{~kg}^{-1}\right)$, which was about 1000 times more than potassium content for ethanolysis itself $\left(10-20 \mathrm{mg} \mathrm{kg}^{-1}\right)$ [23]. The formed butyl ester caused high solubility of potassium soaps in the EP. Similar effect was also observed for methyl esters, but much less intensively (please refer to section 3.2.1). For this reason, ethanol for transesterification was not studied in detailed (as for methanol).

\subsubsection{The influence of various molar ratios of oil : methanol : butanol}

The various molar ratios of O:M:B were used for transesterification. The molar ratios were found in the ternary plot (Fig 1A) so that the reaction mixture was homogeneous with minimum alcohol use. For all molar ratios, the amount of catalyst was $0.8 \mathrm{wt} \%$ to oil and the temperature $60{ }^{\circ} \mathrm{C}$, because it is the usual temperature of transesterification with methanol 
only. Moreover, the reaction was stopped by two different ways. The dependency of $w_{e s t e r}$ in

193 the EP on the reaction time was determined and compared with methanolysis itself (Fig 2).

194 If the molar ratio O:M:B was 1:6:2.3, which is the same as is usually used for single 195 methanol $(\mathrm{O}: \mathrm{M}=1: 6)$, the $w_{\text {ester }}$ in the EP was $97 \%$ after $10 \mathrm{~min}$. In the case of 196 transesterification with only methanol, the same yield was achieved after 80 min of reaction 197 (under the same reaction conditions). Therefore, the reaction time was rapidly decreased by 198 butanol addition, because butanol acted as a cosolvent. Moreover, butanol also reacted with 199 oil, because $15 \mathrm{~mol} \%$ of butyl ester was found in the EP. For lower molar ratios, the transesterification was slower, because methanol was presented in lower amount. For molar ratio O:M:B 1:4.6:1.5 (molar ratio of oil to alcohol M:B 1:6.1), the reaction was slightly faster 202 than reaction with only methanol. For the lowest molar ratio of alcohols (1:4.7), which was less than for methanol itself, the reaction was the slowest and $w_{\text {ester }}$ in the EP was lower than

204 for only methanol. However, for lower molar ratios of alcohols, the content of butyl esters in 205 the EP was also lower (between 7-9 mol\%), because less amount of butanol was used. Boocok, et al. published methyl terc-butyl ether as cosolvent for transesterification with conversion $95 \%$ after $20 \mathrm{~min}$.

Moreover, the properties of the EP and GP were determined. The acid number of the EP

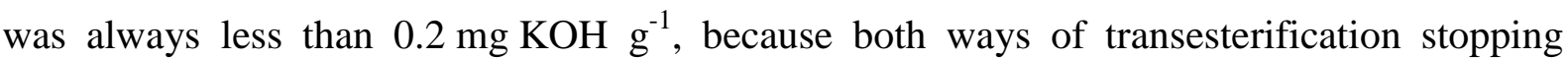
210 ensure low acid number [19]. The density of EP was in the range $0.874-0.880 \mathrm{~g} \mathrm{~cm}^{-3}$ for all 211 molar ratios and ways of stopping. The viscosity was determined $5.1 \mathrm{~mm}^{2} \mathrm{~s}^{-1}$, which was 212 higher than for pure methyl esters, because the EP contains mixture of methyl and butyl 213 esters. This was proved by the determination of viscosity of the mixture of methyl and butyl

214 esters (as molar percent of butyl esters in the mixture - $x_{B E}^{E P}$ ) (Fig. 3A). The viscosity 215 increased with increasing butyl ester content and viscosity of butyl ester was about $32 \%$ higher than methyl esters. The flash point higher than $130{ }^{\circ} \mathrm{C}$ of the EP was also determined, 
which means that the residual content of alcohols is less than $0.08 \mathrm{wt} \%$ for methanol and $2180.13 \mathrm{wt} \%$ for butanol (both were determined by GC). The content of butanol was higher 219 because is less volatile than methanol.

The water content and content of potassium ions were quite high (Table 1) in comparison with transesterification with only methanol, but the purification step was not used. Higher water content was also determined for pure butyl ester $(1360 \mathrm{ppm})$ than for pure methyl esters (650 ppm) without drying. The amount of water was higher for stopping by $\mathrm{H}_{3} \mathrm{PO}_{4}$ than by $\mathrm{CO}_{2}$. The relatively high content of these impurities was caused by formed butyl ester. The reason is that the potassium ions are more soluble in butyl esters than in methyl ester, which was confirmed by independent experiments: the potassium soaps were solved in the esters, which were prepared by mixing of pure methyl and pure butyl esters with various esters compositions. The content of solved potassium ions was determined by flame photometry (Fig. 3B). The content of potassium increased with increasing content of butyl esters in the mixture and was approximately 3.5 times higher for pure butyl ester than for methyl esters. Therefore, the presence of butyl esters increase the potassium and water content in EP without 232 purifications. Note: the exact content of potassium and water content depends also on the 233 separation and purifications steps.

234 The side GP was also analysed in detail (Table 1), including the content of esters in the 235 GP, i.e. esters loss $\left(w_{\text {ester }}^{G P}\right)$, which is different from other papers. The content of ester in the GP 236 (19-25 wt\%) was higher than in the GP prepared by transesterification with only methanol, 237 where it was approximately $10 \mathrm{wt} \%$ [18]. For butanol, the ester content in the GP has not 238 been published yet. Moreover, the ester content was higher for stopping by $\mathrm{H}_{3} \mathrm{PO}_{4}$ than by $239 \mathrm{CO}_{2}$. The GP contains also inorganic salts $\left(w_{I S}\right)$, which were formed by catalyst neutralization 240 and depend on the type of reaction stopping $\left(\mathrm{K}_{2} \mathrm{HPO}_{4}\right.$ for stopping by $\mathrm{H}_{3} \mathrm{PO}_{4}$ and $\mathrm{K}_{2} \mathrm{CO}_{3}$, $241 \mathrm{KHCO}_{3}$ for stopping by $\mathrm{CO}_{2}$ ). The content of these salts was low, which detected that almost 
no catalyst remained at the end of the reaction, i.e. almost all was consumed by side reaction -

243 saponification. The content of water was quite low, from 0.3 to $0.9 \mathrm{wt} \%$.

\subsubsection{The influence of reaction temperature}

245 The influence of temperature was also studied: two temperatures were chosen $\left(25\right.$ and $\left.60{ }^{\circ} \mathrm{C}\right)$

246 and appropriate molar ratios of alcohol to oil, minimum so that mixture was homogeneous, 247 were determined from the ternary plot (Fig. 1A). For $25^{\circ} \mathrm{C}$, the amount of butanol has to be 248 higher (molar ratio O:M:B 1:5:4.7, i.e. approximate molar ratio $\mathrm{M}$ to $\mathrm{B}$ was 1:1) than for $24960{ }^{\circ} \mathrm{C}$ (molar ratio O:M:B 1:6:2.3, i.e. molar ratio $\mathrm{M}$ to $\mathrm{B}$ was $2.6: 1$ ). The dependency of ester 250 content in the EP ( $\left.w_{\text {ester }}\right)$ on the reaction time was determined (Fig. 4) and compared with 251 single methanol used. For $60{ }^{\circ} \mathrm{C}$, the ester content was $97 \mathrm{wt} \%$ after $10 \mathrm{~min}$, while only 252 methanol was $88.3 \mathrm{wt} \%$. The difference of ester content was greater for lower temperature $253\left(25^{\circ} \mathrm{C}\right)$, where the miscibility of the reaction mixture has stronger influence $(85 \%$ after 80 254 min for methanol only). The mixture of methyl and butyl esters was formed.

The analysis of both phases was also carried out (Table 2). The viscosity, water content 256 and potassium content were higher than for pure methyl esters, because the butyl ester caused 257 higher solubility of potassium ions, which was discussed above (Fig. 3). The content of ester 258 in the GP was higher for higher temperature, because higher temperature caused higher 259 solubility.

\subsubsection{The influence of catalyst amounts}

261 The influence of catalyst (in the range 0.7-0.9 wt\% to oil) was studied (Table 3). Moreover, 262 the reaction was stopped by two ways as in previous cases. Higher catalyst amount means 263 higher amount ester in the EP. On the other hand, higher catalyst amount caused higher 264 saponification, which was expected, and so higher content of ester in the GP (ester loss). The 
content of potassium ions was lower for stopping by $\mathrm{H}_{3} \mathrm{PO}_{4}$ than $\mathrm{CO}_{2}$, which is in accordance with previous papers, where the similar phenomena was also described [19].

\subsubsection{Ester loss and distribution of esters}

268 The ester loss (determined as the content of esters in the GP in wt $\%$ ) was analysed, which is very often omitted in papers. The content of esters was approximately in the range $15-25 \mathrm{wt} \%$ (Table 4), which was higher than for pure methyl esters (9-10 wt $\%)$. Therefore, the formed 271 butyl ester caused higher ester loss.

Moreover, the distribution of esters according to alcohols, i.e. methyl esters (ME) and 273 butyl esters (BE), was also determined for both phases (Table 4). The content of methyl ester 274 in the EP was in the range from $85 \mathrm{~mol} \%$ to $92 \mathrm{~mol} \%$ at $60{ }^{\circ} \mathrm{C}$, while at $25^{\circ} \mathrm{C}$ it was lower, 275 around $80 \mathrm{~mol} \%$. However, the initial molar ratio of methanol to butanol used for the 276 transesterification was $52.4 \mathrm{~mol} \%$ at $25^{\circ} \mathrm{C}$ and $73-77.8 \mathrm{~mol} \%$ at $60{ }^{\circ} \mathrm{C}$ of methanol in the 277 alcohols mixture. According to stoichiometry of transesterification, one mole of alcohol forms 278 one mole of ester. The ratio between molar percent of methyl esters in EP and molar percent 279 of methanol in alcohol mixture was calculated. The ratio "one" means the same molar ratio of 280 methanol and formed methyl ester. For lower temperature $\left(25^{\circ} \mathrm{C}\right)$, more methyl esters were 281 formed from methanol than butyl esters from butanol: $80 \mathrm{~mol} \%$ of methyl ester in the EP was 282 formed from $52.4 \mathrm{~mol} \%$ of methanol, the ratio was 1.52 . For higher temperature $\left(60{ }^{\circ} \mathrm{C}\right)$, the 283 ratio was lower, 1.19. This ratio depends only on the temperature and not on other reaction 284 conditions.

Only smaller amount of butanol was converted to butyl esters and butanol acted mainly as a cosolvent. Therefore, for lower temperature, the methyl esters are easily formed than 287 butyl esters. The reason is probably lower activation energy for transesterification by 288 methanol than by butanol. However, it is inconclusive, because the activation energy was 289 published in a wide range, which depends on the simplification of kinetic model, type of oil, 
type of catalyst and transesterification conditions. The activation energy was published for 291 methanolysis from 12 to $104 \mathrm{~kJ} \mathrm{~mol}^{-1}$ [24] and for ethanolysis from 3.4 to $70.6 \mathrm{~kJ} \mathrm{~mol}^{-1}$ [25].

292 The activation energy for transesterification with butanol was not published. Moreover, the 293 formed oil is immiscible with methanol, while miscible with butanol, which complicated the 294 calculation. The positive correlation between content of methyl esters in GP and content of 295 methyl esters in EP was found (Fig. 5).

296 The dependency of distribution of methyl and butyl ester in the EP and GP on the transesterification stopping $\left(\mathrm{CO}_{2}\right.$ or $\left.\mathrm{H}_{3} \mathrm{PO}_{4}\right)$ was determined. In the case of stopping by $\mathrm{CO}_{2}$, the distribution of methyl and butyl esters between the EP and GP was approximately the same, i.e. the relative content of methyl esters in the EP and GP was almost the same. The relative content did not depend on the reaction conditions. However, the distribution was

301 different for stopping by $\mathrm{H}_{3} \mathrm{PO}_{4}$ : more methyl esters were presented in the GP than in the EP. Therefore, the stopping by $\mathrm{H}_{3} \mathrm{PO}_{4}$ caused more solubility of methyl ester in the GP than stopping by $\mathrm{CO}_{2}$.

\subsection{Transesterification by heterogeneous catalyst}

305 The transesterification with heterogeneous catalyst was also tested. The $\mathrm{Mg}$-Fe mixed oxide 306 with molar ratio $\mathrm{Mg} / \mathrm{Fe}$ 3:1 was used as heterogeneous catalyst. The active coal, which was 307 added during synthesis of hydrotalcite, was removed by calcination at $450{ }^{\circ} \mathrm{C}$. The 308 determination by XRD (Fig. 6) confirmed the structure of mixed oxide by presentation of 309 typical diffraction lines for mixed oxide (JCPDS database). In hydrotalcite, the real molar 310 ratio of magnesium to iron 2.9 was determined by ICP analysis (1.55 mol Mg and $0.53 \mathrm{~mol}$

311 Fe), i.e. almost as the same as expected. The specific surface area was calculated by fitting of 312 experimental data determine by nitrogen adsorption-desorption isotherms with use BET

313 isotherm. The surface area of $\mathrm{Mg} / \mathrm{Fe} 3: 1$ with $1.25 \mathrm{wt} \%$ of coal was $132 \mathrm{~m}^{2} \mathrm{~g}^{-1}$ which was 
314 compared with hydrotalcite $\mathrm{Mg} / \mathrm{Fe} 3: 1$ without addition of active coal $\left(101 \mathrm{~m}^{2} \mathrm{~g}^{-1}\right)$. The high

315 surface area is important, because transesterification carried out on the surface of catalyst.

316 The catalyst activity was tested in transesterification of rapeseed oil with (i) only methanol,

317 (ii) only butanol and (iii) various ratios of methanol to butanol. The best results were achieved

318 with methanol and mixture of methanol and butanol in molar ratio 1:1. The content of esters

319 in the EP reached 97.5 wt.\% after $4 \mathrm{~h}$ of reaction, which is much faster than published in [20],

320 where it was only $70 \mathrm{wt} . \%$ after the reaction time of $6 \mathrm{~h}$. In the case of using only butanol, the

321 ester content in the EP was 59.4 wt.\%, because butanol is less reactive than methanol. The

322 addition of butanol increase the reaction rate and so decrease the reaction time.

\section{CONCLUSIONS}

This work described the use of butanol as the cosolvent for transesterification of oil by methanol or ethanol under homogeneous and also heterogeneous catalyst. The ternary plots with binodal curve for reaction components (oil, methanol/ethanol and butanol) were determined for two temperatures $\left(25\right.$ and $\left.60{ }^{\circ} \mathrm{C}\right)$ to find the homogeneous region. For homogeneous catalyst, the transesterification was carried out with various reaction condition. The ester yield was $97 \%$ after 10 min of reaction for $60^{\circ} \mathrm{C}$ and ratio O:M:B 1:6:2. However,

330 the viscosity and content of potassium ions were higher than for pure methyl ester (without 331 purification), because the solubility of potassium soaps increased with increasing butyl ester 332 content in the mixture of esters. The distribution of methyl and butyl esters in both phases was determined. It was found, that the content of methyl esters was higher than corresponding

334 methanol in the alcohol mixture, especially at lower temperature. The attention was also 335 focused on the detailed analysis of the side GP where the content of esters was higher for 336 higher temperature. 
The use of butanol decrease the production cost and improves the total energy balance of

biodiesel production and so increases sustainability, because transesterification proceeds in

single phase and moreover formed butyl ester has higher caloric value.

\section{ACKNOWLEDGEMENTS}

This work was supported by the Czech Science Foundation, Project No. 19-00669S.

\section{REFERENCES}

[1] Kiwjaroun C, Tubtimdee C, Piumsomboon P. LCA studies comparing biodiesel synthesized by conventional and supercritical methanol methods. J Clean Prod 2009;17(2):143-53. https://doi.org/10.1016/j.jclepro.2008.03.011

[2] Meher LC, Sagar DV, Naik SN. Technical aspects of biodiesel production by transesterification - a review. Renewable \& Sustainable Energy Reviews 2006;10(3):24868. https://doi.org/10.1016/j.rser.2004.09.002

[3] Silitongaa AS, Masjukia HH, Hwai Chyuan Onga, Kusumoa F, Mahliac TMI, Baharc AH. Pilot-scale production and the physicochemical properties of palm and Calophyllum inophyllum biodiesels and their blends. J Clean Prod 2016;126:654-66. https://doi.org/10.1016/j.jclepro.2016.03.057

[4] Tan SX, Lim S, Ong HC, Pang YL. State of the art review on development of ultrasoundassisted catalytic transesterification process for biodiesel production. Fuel 2019;235:886907. https://doi.org/10.1016/j.fuel.2018.08.021

[5] Guldhe A, Singh B, Mutanda T, Perrnaul K, Bux F. Advances in synthesis of biodiesel via enzyme catalysis: Novel and sustainable approaches. Renew Sust Energ Rev 2015;41:1447-64. https://doi.org/10.1016/j.rser.2014.09.035

[6] Issariyakul T, Kulkarni MG, Dalai AK, Bakhshi NN. Production of biodiesel from waste Eryer grease using mixed methanol/ethanol system. Fuel Process Technol 2007;88(5):429-36. https://doi.org/10.1016/j.fuproc.2006.04.007

[7] Guan G, Kusakabe K, Sakurai N, Moriyama K. Transesterification of vegetable oil to biodiesel fuel using acid catalysts in the presence of dimethyl ether. Fuel 2009;88(1):816. https://doi.org/10.1016/j.fuel.2008.07.021

[8] Todorovic ZB, Stamenkovic OS, Stamenkovic IS, Avramovic JM, Velickovic AV, Bankovic-Ilic IB, et al. The effects of cosolvents on homogeneously and heterogeneously base-catalyzed methanolysis of sunflower oil. Fuel 2013;107:493-502. https://doi.org/10.1016/j.fuel.2012.11.049

[9] Ataya F, Dube MA, Ternan M. Single-phase and two-phase base-catalyzed transesterification of canola oil to fatty acid methyl esters at ambient conditions. Ind Eng Chem Res 2006;45(15):5411-7. https://doi.org/10.1021/ie060152o

[10] Guan GQ, Sakurai N, Kusakabe K. Synthesis of biodiesel from sunflower oil at room temperature in the presence of various cosolvents. Chem Eng J 2009;146(2):302-6. https://doi.org/10.1016/j.cej.2008.10.009

[11] Nimcevic D, Puntigam R, Worgetter M, Gapes JR. Preparation of rapeseed oil esters of lower aliphatic alcohols. J Am Oil Chem Soc 2000;77(3):275-80. https://doi.org/10.1007/s11746-000-0045-1 
[12]Leadbeater NE, Barnard TM, Stencel LM. Batch and continuous-flow preparation of biodiesel derived from butanol and facilitated by microwave heating. Energ Fuel 2008;22(3):2005-8. https://doi.org/Doi 10.1021/Ef700748t

[13] Bynes AN, Eide I, Jorgensen KB. Optimization of acid catalyzed transesterification of jatropha and rapeseed oil with 1-butanol. Fuel 2014;137:94-9. https://doi.org/10.1016/j.fuel.2014.07.085

[14] Navas MB, Lick ID, Bolla PA, Casella ML, Ruggera JF. Transesterification of soybean and castor oil with methanol and butanol using heterogeneous basic catalysts to obtain biodiesel. Chem Eng Sci 2018;187:444-54. https://doi.org/10.1016/j.ces.2018.04.068

[15]Zhao T, Choi N, Kim H, Kim Y, Kim HR, Kim IH. Lipase-Mediated Synthesis of Fatty Acid Esters Using a Blending Alcohol Consisting of Methanol and 1-Butanol. J Am Oil Chem Soc 2017;94(4):559-65. https://doi.org/10.1007/s11746-017-2967-1

[16] Jha MK, Gupta AK, Kumar V. Kinetics of transesterification on Jatropha curcas oil to biodiesel fuel. Wcecs 2007: World Congress on Engineering and Computer Science 2007:99-102.

[17] Sanjid A, Masjuki HH, Kalam MA, Rahman SMA, Abedin MJ, Palash SM. Production of palm and jatropha based biodiesel and investigation of palm-jatropha combined blend properties, performance, exhaust emission and noise in an unmodified diesel engine. $\mathbf{J}$ Clean Prod 2014;65:295-303. https://doi.org/10.1016/j.jclepro.2013.09.026

[18]Hajek M, Kwiecien J, Skopal F. Biodiesel: The influence of dealcoholization on reaction mixture composition after neutralization of catalyst by carbon dioxide. Fuel 2012;96(1):85-9. https://doi.org/10.1016/j.fuel.2012.01.037

[19] Vavra A, Hajek M, Skopal F. Acceleration and simplification of separation by addition of inorganic acid in biodiesel production. J Clean Prod 2018;192:390-5. https://doi.org/10.1016/j.jclepro.2018.04.242

[20] Hajek M, Tomasova A, Kocik J, Podzemna V. Statistical evaluation of the mutual relations of properties of $\mathrm{Mg} / \mathrm{Fe}$ hydrotalcites and mixed oxides as transesterification catalysts. Applied Clay $\quad$ Science 2018;154:28-35. https://doi.org/10.1016/j.clay.2017.12.039

[21] Komers K, Stloukal R, Machek J, Skopal F, Komersova A. Biodiesel fuel from rapeseed oil, methanol, and $\mathrm{KOH}$. Analytical methods in research and production. Fett-Lipid 1998;100(11):507-12. https://doi.org/10.1002/1438-9312(200106)103:6<363::AIDEJLT363>3.0.CO;2-3

[22] Rumble J, Lide D, Macdonald F. Chemical safety data in the Handbook of Chemistry and Physics. Abstracts of Papers of the American Chemical Society 2018;255.

[23] Cernoch M, Hajek M, Skopal F. Study of effects of some reaction conditions on ethanolysis of rapeseed oil with dispergation. Bioresource Technol 2010;101(4):1213-9. https://doi.org/10.1016/j.biortech.2009.09.033

[24] Marjanovic AV, Stamenkovic OS, Todorovic ZB, Lazic ML, Veljkovic VB. Kinetics of the base-catalyzed sunflower oil ethanolysis. Fuel 2010;89(3):665-71. https://doi.org/10.1016/j.fuel.2009.09.025

[25] Shahla S, Ngoh GC, Yusoff R. The evaluation of various kinetic models for basecatalyzed ethanolysis of palm oil. Bioresour Technol 2012;104:1-5. https://doi.org/10.1016/j.biortech.2011.11.010 


\section{$424 \quad$ Figure captions}

426 Fig. 1: The ternary plots of M:O:B (A) and E:O:B (B) at two temperatures

427 Fig. 2: The dependency of $w_{\text {ester }}$ in the EP on the reaction time for different molar ratios of alcohols to oil at $60{ }^{\circ} \mathrm{C}$ and $0.8 \mathrm{wt} \%$ of catalyst to oil

429 Fig. 3: The dependency of viscosity (A) and content of potassium ions (B) on the molar ratios of butyl esters in the mixture of methyl and butyl esters

431 Fig. 4. The dependency of $w_{\text {ester }}$ on the reaction time for different reaction temperatures at $0.8 \mathrm{wt} \%$ of catalyst to oil, molar ratio O:M:B 1:5:4.7 for $25^{\circ} \mathrm{C}$ and $1: 6: 2.3$ for $60{ }^{\circ} \mathrm{C}$

433 Fig. 5: The correlation of methyl esters between the EP and GP

434 Fig. 6: The diffractogram of Mg-Fe mixed oxides 
Table 1: The properties of the EP and the GP after transesterification with different molar ratios of O:M:B (temperature $60{ }^{\circ} \mathrm{C}$, time 80 min, catalyst $0.8 \mathrm{wt} \%$ to oil)

\begin{tabular}{|c|c|c|c|c|c|c|c|c|c|c|c|c|}
\hline \multirow[b]{2}{*}{ Stop by } & \multirow[b]{2}{*}{$\begin{array}{c}\text { Molar ratio } \\
\text { O:M:B }\end{array}$} & \multicolumn{6}{|c|}{ The ester phase } & \multicolumn{5}{|c|}{ The glycerol phase } \\
\hline & & $\begin{array}{l}w_{\text {ester }}, \\
\text { wt. } \%\end{array}$ & $\begin{array}{c}\text { water } \\
\text { ppm }\end{array}$ & $\begin{array}{c}K \\
\mathrm{mg} \mathrm{kg}^{-1}\end{array}$ & $\begin{array}{l}w_{M G}, \\
\text { wt. } \%\end{array}$ & $\begin{array}{l}w_{D G}, \\
\text { wt. } \%\end{array}$ & $\begin{array}{l}w_{T G}, \\
\text { wt. } \%\end{array}$ & $\begin{array}{c}w_{\text {glycerol }} \\
\text { wt. } \%\end{array}$ & $\begin{array}{l}w_{e s t e r}^{G P}, \\
\text { wt. } \%\end{array}$ & $\begin{array}{c}w_{S}, \\
\text { wt. } \%\end{array}$ & $\begin{array}{l}w_{I S}, \\
\text { wt. } \%\end{array}$ & $\begin{array}{l}w_{\text {water }}, \\
\text { wt. } \%\end{array}$ \\
\hline \multirow{3}{*}{$\mathrm{CO}_{2}$} & 1:6.0:2.3 & 98.7 & 960 & 100 & 0.78 & 0.31 & 0.25 & 61.5 & 21.0 & 14.8 & 2.48 & 0.47 \\
\hline & 1:4.6:1.5 & 96.7 & 600 & 168 & 2.05 & 0.56 & 0.72 & 64.8 & 20.8 & 16.9 & 1.58 & 0.29 \\
\hline & 1:3.9:1.1 & 96.1 & 720 & 259 & 1.71 & 1.11 & 1.03 & 62.4 & 18.7 & 16.5 & 1.71 & 0.66 \\
\hline \multirow{3}{*}{$\mathrm{H}_{3} \mathrm{PO}_{4}$} & 1:6.0:2.3 & 97.9 & 1090 & 22 & 1.84 & 0.24 & 0.07 & 62.3 & 21.8 & 19.8 & 0.49 & 0.51 \\
\hline & 1:4.6:1.5 & 95.7 & 1068 & 100 & 3.54 & 0.71 & 0.09 & 56.7 & 24.5 & 18.3 & 0.62 & 0.56 \\
\hline & $1: 3.9: 1.1$ & 95.1 & 1114 & 136 & 3.53 & 1.03 & 1.32 & 43.7 & 37.9 & 15.2 & 0.59 & 0.43 \\
\hline
\end{tabular}


Table 2: The properties of the EP and the GP after transesterification at different temperature and reaction stopping (time 80 min, catalyst $0.8 \mathrm{wt} \%$ to oil)

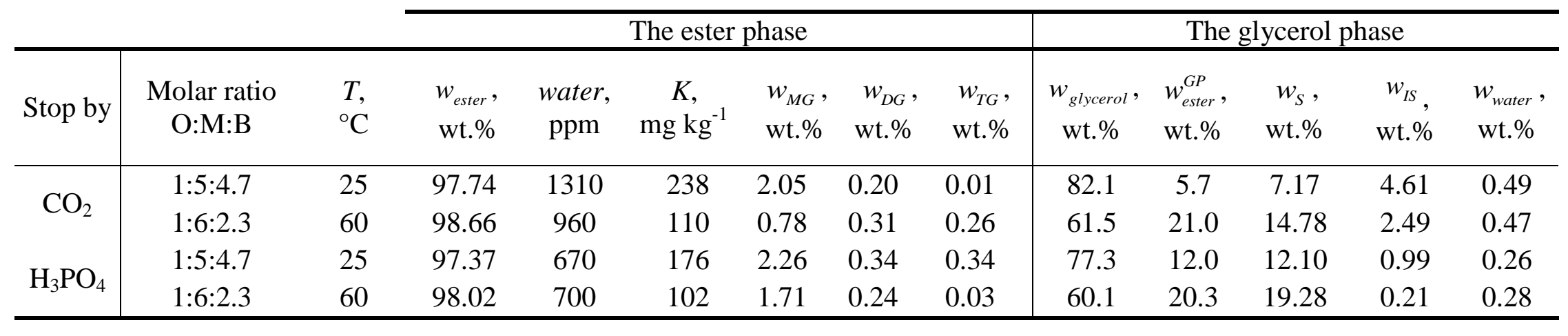


Table 3: The properties of the EP and the GP after transesterification with different catalyst amount (temperature $60{ }^{\circ} \mathrm{C}$ and time 80 min)

\begin{tabular}{|c|c|c|c|c|c|c|c|c|c|c|c|c|}
\hline \multirow[b]{2}{*}{ Stop by } & \multirow[b]{2}{*}{$\begin{array}{c}\text { Catalyst } \\
\text { amount, } \\
\text { wt.\% }\end{array}$} & \multicolumn{6}{|c|}{ The ester phase } & \multicolumn{5}{|c|}{ The glycerol phase } \\
\hline & & $\begin{array}{l}w_{\text {ester }} \\
\text { wt.\% }\end{array}$ & $\begin{array}{c}\text { water, } \\
\text { ppm }\end{array}$ & $\begin{array}{c}K, \\
\mathrm{mg} \mathrm{kg}^{-1}\end{array}$ & $\begin{array}{l}w_{M G}, \\
\text { wt. } \%\end{array}$ & $\begin{array}{l}w_{D G}, \\
\text { wt. } \%\end{array}$ & $\begin{array}{l}w_{T G}, \\
\text { wt. } \%\end{array}$ & $\begin{array}{c}w_{\text {glycerol }} \\
\text { wt. } \%\end{array}$ & $\begin{array}{l}w_{\text {ester }}^{G P} \text {, } \\
\text { wt. } \%\end{array}$ & $\begin{array}{c}w_{S}, \\
\text { wt. } \%\end{array}$ & $\begin{array}{l}w_{I S}, \\
\text { wt. } \%\end{array}$ & $\begin{array}{l}w_{\text {water }}, \\
\text { wt. } \%\end{array}$ \\
\hline \multirow{3}{*}{$\mathrm{CO}_{2}$} & 0.7 & 96.30 & 960 & 104 & 2.34 & 0.58 & 0.78 & 63.8 & 16.6 & 16.2 & 2.17 & 0.32 \\
\hline & 0.8 & 96.67 & 600 & 168 & 2.05 & 0.56 & 0.72 & 62.8 & 17.5 & 17.9 & 1.57 & 0.29 \\
\hline & 0.9 & 97.28 & 720 & 111 & 2.04 & 0.35 & 0.34 & 57.8 & 23.0 & 19.2 & 1.49 & 0.20 \\
\hline \multirow{3}{*}{$\mathrm{H}_{3} \mathrm{PO}_{4}$} & 0.7 & 95.35 & 1179 & 43 & 3.80 & 0.62 & 0.22 & 67.5 & 14.0 & 16.6 & 1.18 & 0.77 \\
\hline & 0.8 & 96.12 & 1075 & 34 & 2.93 & 0.49 & 0.46 & 65.9 & 15.3 & 17.5 & 0.37 & 0.92 \\
\hline & 0.9 & 96.84 & 798 & 38 & 2.85 & 0.25 & 0.06 & 52.5 & 23.9 & 20.9 & 0.08 & 0.55 \\
\hline
\end{tabular}


Table 4: The loss of esters in the GP ( $\left.w_{\text {ester }}^{G P}\right)$ including the distribution according to methyl and butyl esters

\begin{tabular}{cccccccc}
\hline Way of stop & $T,{ }^{\circ} \mathrm{C}$ & $\begin{array}{c}\text { Molar ratio } \\
\text { of M:B }\end{array}$ & $\begin{array}{c}\text { Molar percent } \\
\text { of methanol in } \\
\text { alcohols }\end{array}$ & $\begin{array}{c}w_{\text {ester }}^{G P}, \\
w t . \%\end{array}$ & $\begin{array}{c}\text { Distribution of ME in } \\
\text { the EP, } \\
\text { mol, } \%\end{array}$ & $\begin{array}{c}\text { Ratio between } \\
\text { the GP, } \\
\text { mol, } \%\end{array}$ & $\begin{array}{c}\text { ME in the EP and M } \\
\text { in alcohols }\end{array}$ \\
\hline $\mathrm{CO}_{2}$ & 25 & $5.0: 4.7$ & 52.4 & 5.7 & 79.5 & 76.8 & 1.5 \\
$\mathrm{CO}_{2}$ & 25 & $5.0: 4.7$ & 52.4 & 7.9 & 79.9 & 77.3 & 1.5 \\
$\mathrm{H}_{3} \mathrm{PO}_{4}$ & 25 & $5.0: 4.7$ & 52.4 & 12.0 & 80.9 & 83.4 & 1.5 \\
$\mathrm{H}_{3} \mathrm{PO}_{4}$ & 25 & $5.0: 4.7$ & 52.4 & 10.9 & 80.8 & 76.4 & 1.5 \\
$\mathrm{CO}_{2}$ & 60 & $6.0: 1.5$ & 73.0 & 21.0 & 85.1 & 85.4 & 1.2 \\
$\mathrm{CO}_{2}$ & 60 & $4.6: 1.5$ & 75.6 & 18.7 & 92.7 & 92.8 & 1.2 \\
$\mathrm{CO}_{2}$ & 60 & $3.9: 1.1$ & 77.8 & 20.8 & 92.4 & 91.8 & 1.2 \\
$\mathrm{CO}_{2}$ & 60 & $4.6: 1.5$ & 75.6 & 19.6 & 90.3 & 88.7 & 1.2 \\
$\mathrm{CO}_{2}$ & 60 & $4.6: 1.5$ & 75.6 & 23.0 & 92.3 & 92.4 & 1.2 \\
$\mathrm{H}_{3} \mathrm{PO}_{4}$ & 60 & $6.0: 2.3$ & 73.0 & 20.3 & 86.1 & 87.8 & 1.2 \\
$\mathrm{H}_{3} \mathrm{PO}_{4}$ & 60 & $6.0: 2.3$ & 73.0 & 21.8 & 84.8 & 91.6 & 1.2 \\
$\mathrm{H}_{3} \mathrm{PO}_{4}$ & 60 & $4.6: 1.5$ & 75.6 & 24.5 & 89.9 & 94.8 & 1.2 \\
$\mathrm{H}_{3} \mathrm{PO}_{4}$ & 60 & $3.9: 1.1$ & 77.8 & 37.9 & 91.9 & 97.4 & 1.2 \\
$\mathrm{H}_{3} \mathrm{PO}_{4}$ & 60 & $4.6: 1.5$ & 75.6 & 14.0 & 87.6 & 96.6 & \\
$\mathrm{H}_{3} \mathrm{PO}_{4}$ & 60 & $4.6: 1.5$ & 75.6 & 23.9 & 89.3 & 96.4 & 1.2 \\
\hline
\end{tabular}


Click here to download high resolution image
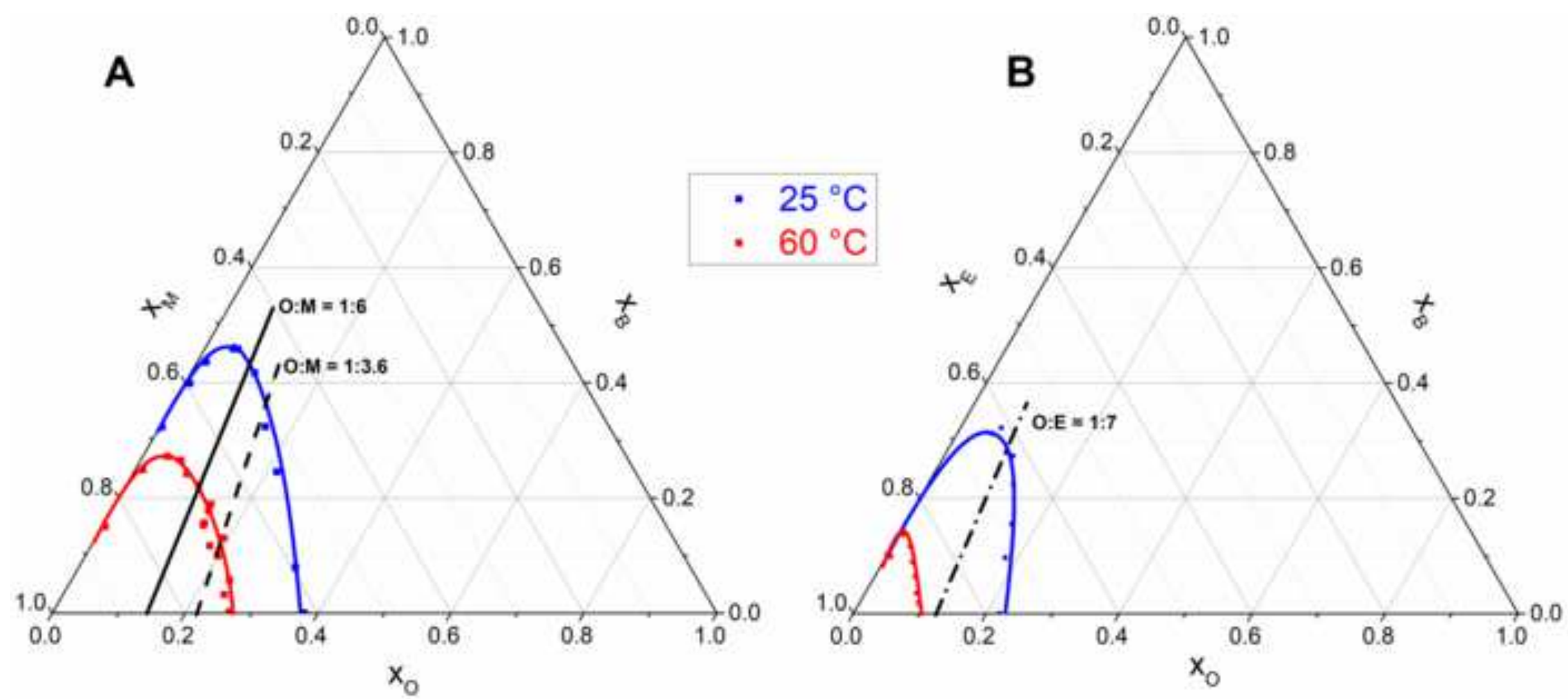


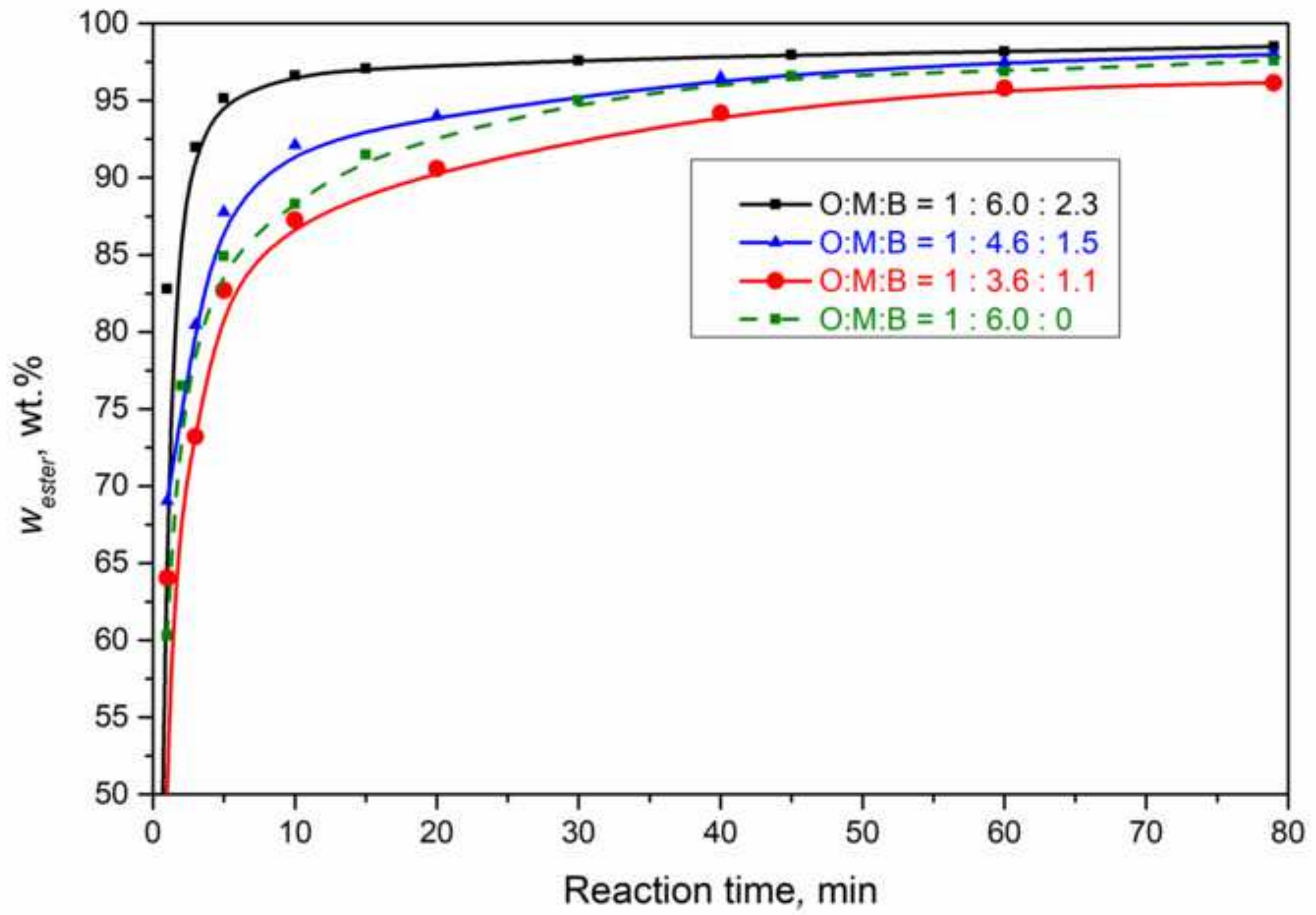



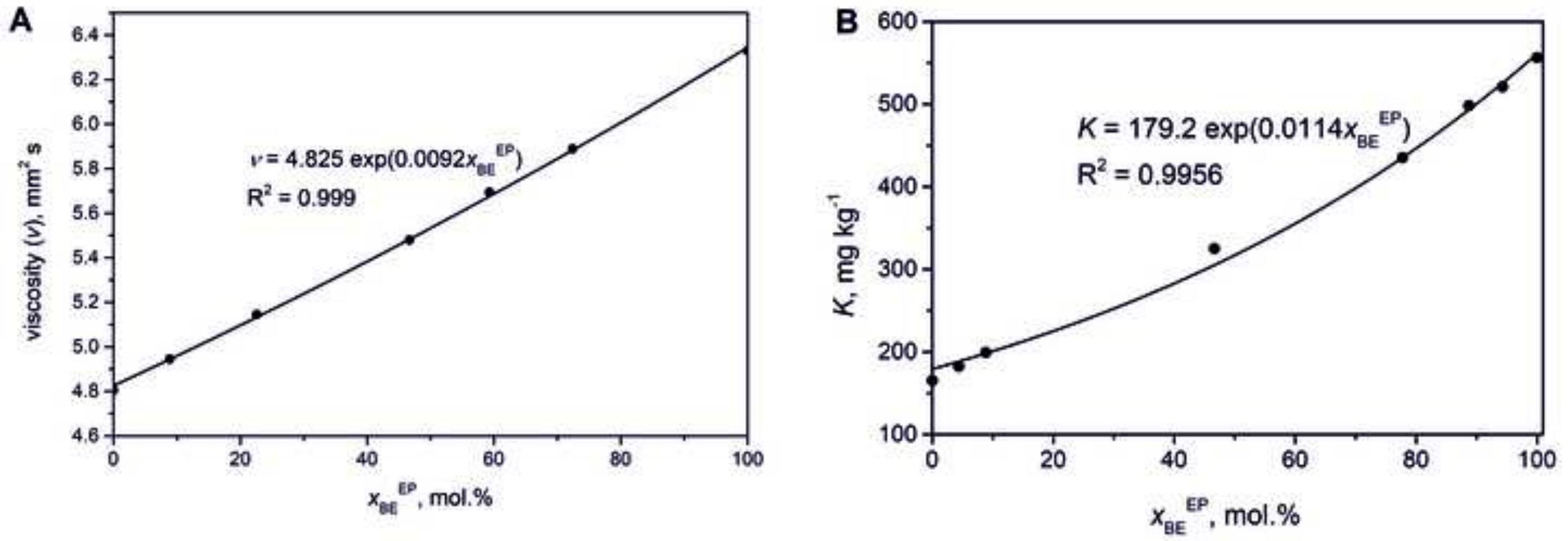


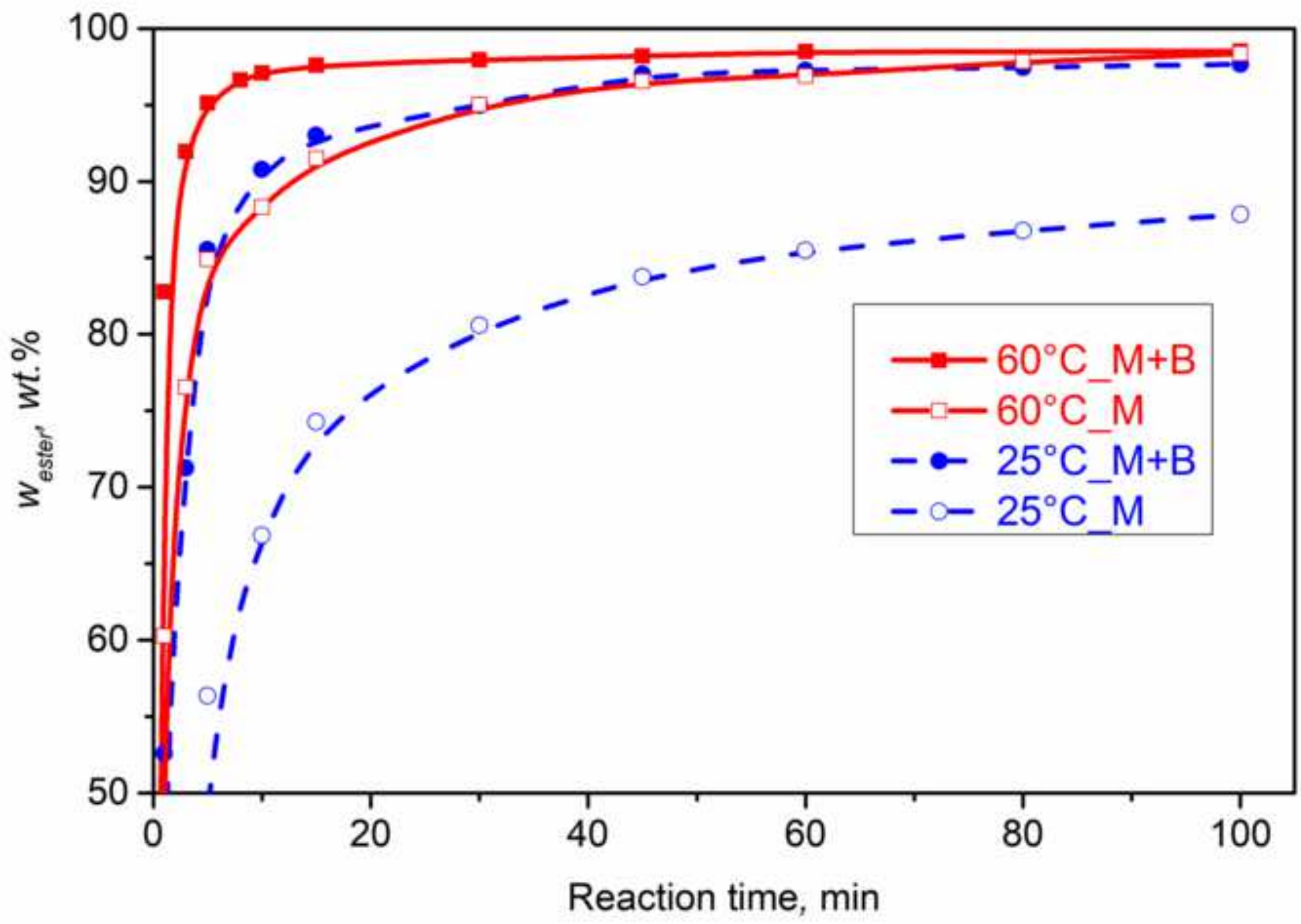




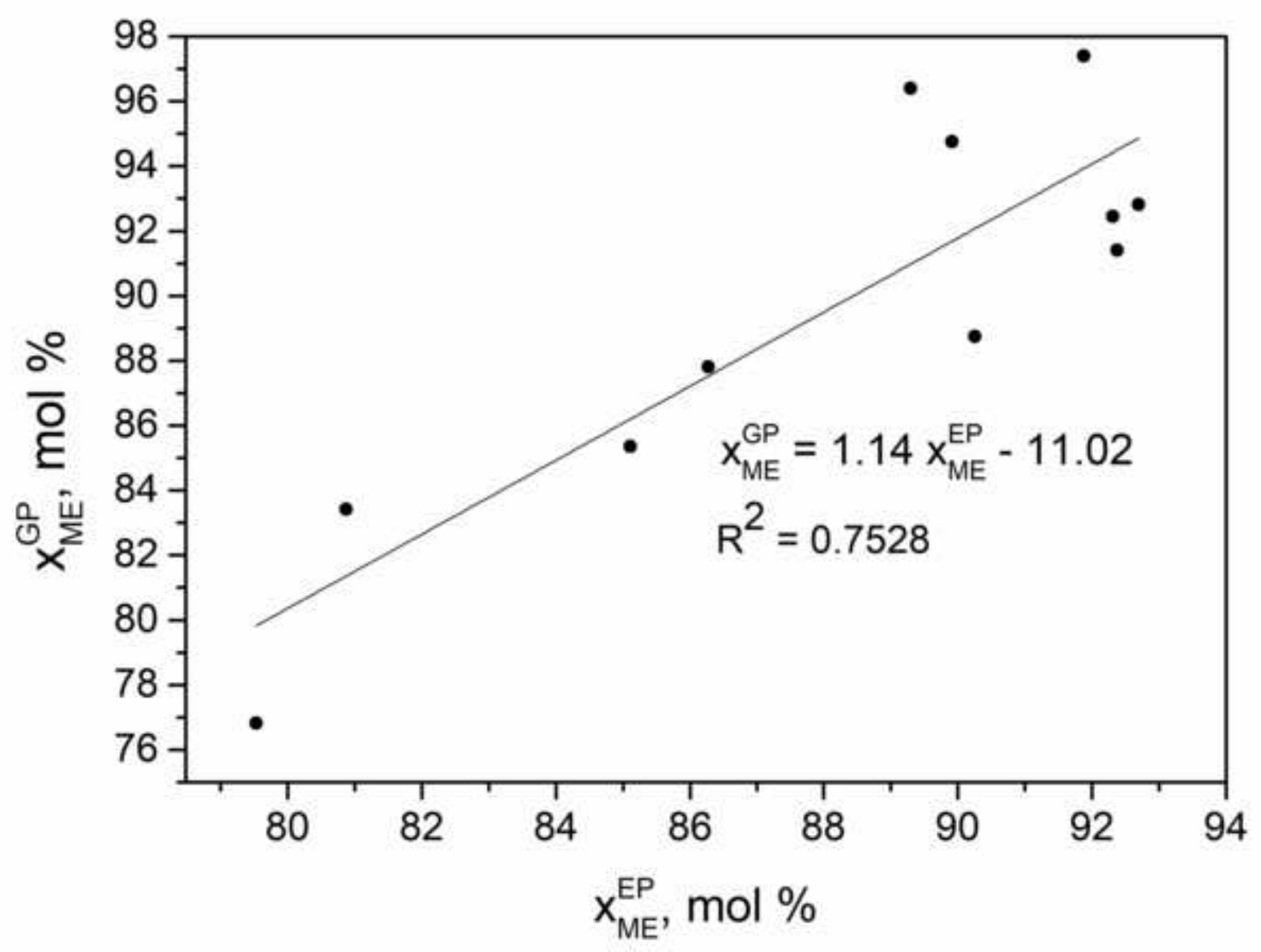




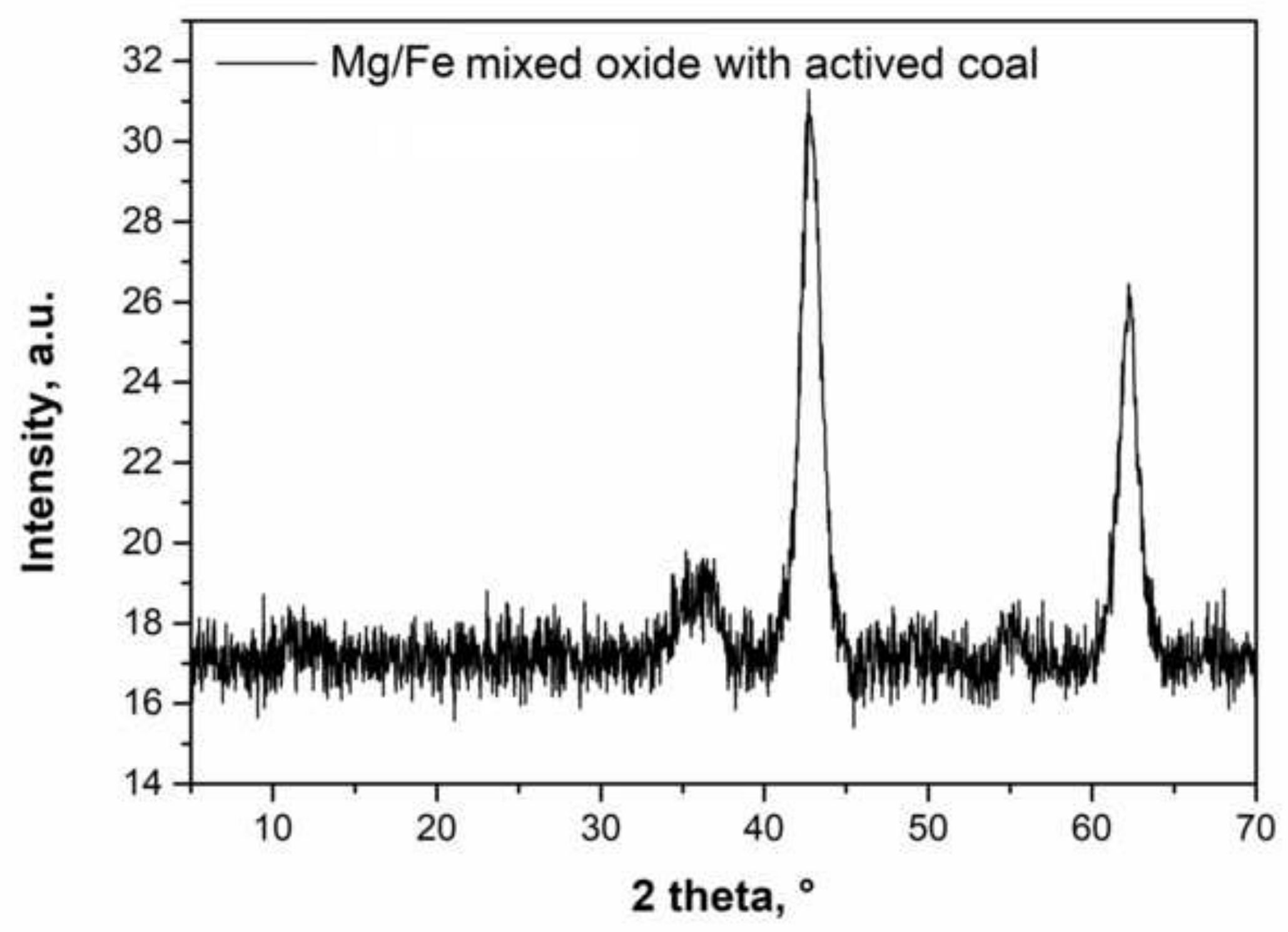

